\title{
Cardiovascular risk assessment in patients with rheumatoid arthritis using carotid ultrasound B-mode imaging
}

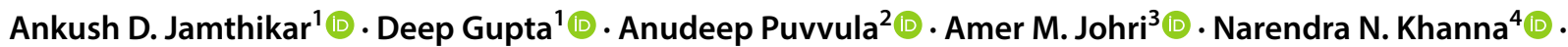

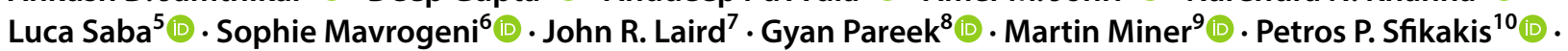

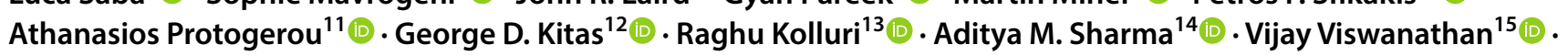 \\ Vijay S. Rathore ${ }^{16}$ (I) Jasjit S. Suri ${ }^{17}$
}

Received: 5 August 2020 / Accepted: 18 August 2020 / Published online: 28 August 2020

(c) Springer-Verlag GmbH Germany, part of Springer Nature 2020

\begin{abstract}
Rheumatoid arthritis (RA) is a systemic chronic inflammatory disease that affects synovial joints and has various extraarticular manifestations, including atherosclerotic cardiovascular disease (CVD). Patients with RA experience a higher risk of CVD, leading to increased morbidity and mortality. Inflammation is a common phenomenon in RA and CVD. The pathophysiological association between these diseases is still not clear, and, thus, the risk assessment and detection of CVD in such patients is of clinical importance. Recently, artificial intelligence (AI) has gained prominence in advancing healthcare and, therefore, may further help to investigate the RA-CVD association. There are three aims of this review: (1) to summarize the three pathophysiological pathways that link RA to CVD; (2) to identify several traditional and carotid ultrasound image-based CVD risk calculators useful for RA patients, and (3) to understand the role of artificial intelligence in CVD risk assessment in RA patients. Our search strategy involves extensively searches in PubMed and Web of Science databases using search terms associated with CVD risk assessment in RA patients. A total of 120 peer-reviewed articles were screened for this review. We conclude that (a) two of the three pathways directly affect the atherosclerotic process, leading to heart injury, (b) carotid ultrasound image-based calculators have shown superior performance compared with conventional calculators, and (c) AI-based technologies in CVD risk assessment in RA patients are aggressively being adapted for routine practice of RA patients.
\end{abstract}

Keywords Arthritis · Rheumatoid · Atherosclerosis · Cardiovascular disease · Inflammation · Carotid artery diseases · Carotid intima-media thickness $\cdot$ Risk assessment

\section{Introduction}

Rheumatoid arthritis (RA) is a chronic inflammatory disease that not affects only synovial joints but also has several extra-articular involvements, including those related to the skin, eyes, heart, lungs, kidneys, and other organs [1, 2]. It affects $\sim 1 \%$ of the global population, with a higher prevalence in females when compared with males [3, 4]. Cardiovascular disease (CVD) is a common manifestation in RA patients with a two- to three-fold higher risk of cardiovascular events and mortality compared with a normal population [5]. However, this increased risk is not entirely

Jasjit S. Suri

jasjit.suri@atheropoint.com

Extended author information available on the last page of the article explained by conventional risk factors [6]. Current statistically derived CVD risk calculators use conventional risk factors alone [7-9], are not suitable for RA patients, and they either underestimate or overestimate the risk [10-12]. This may be because of the paradoxical behavior of some of the conventional risk factors such as body mass index, low-density lipoprotein, high-density lipoprotein, and total cholesterol in RA [13, 14]. Despite this lack of clarity, the guidelines by the European League Against Rheumatism (EULAR) recommend aggressive control of these conventional risk factors $[15,16]$. Recent attempts were made to improve the CVD risk assessment in the RA population, including the development of "RA-specific risk factors" in the CVD risk calculators [17-20]. However, such calculators could not provide adequate improvement in risk 
prediction and reportedly still underestimated or overestimated CVD risk in RA patients [21, 22].

To provide a better CVD risk assessment in RA, a pathophysiological association between these diseases should be understood, as this would help in refining CVD risk predictors in RA patients [23]. Atherosclerosis, a common phenomenon in RA [24, 25], can be adequately monitored using imaging modalities such as magnetic resonance imaging [26], computed tomography [27], optical coherence tomography [28], and ultrasound [29]. Each of these imaging modalities offers unique information about morphological variations in atherosclerotic plaque. Ultrasound imaging, specifically in carotid arteries, is a comparatively low-cost, non-invasive, radiation-free, and easy-to-use imaging modality that is widely adopted in preventive cardiovascular and clinical vascular practices $[29,30]$. The image-based phenotypes of carotid ultrasound, such as carotid intima-media thickness (cIMT) and carotid plaque, are considered surrogate markers of coronary artery disease and have been used for preventive CVD risk assessments in several studies [31-34]. These image-based phenotypes indicate the morphological variations in the atherosclerotic plaque and are associated with the inflammatory markers of RA [35-38]. Patients with RA have elevated cIMT and have more plaque area (PA) when compared with non-RA patients [39-41]. Thus, the inclusion of these image-based phenotypes in risk prediction models may improve the CVD risk assessments of RA patients. Recent studies have combined the effect of these image-based phenotypes with conventional risk factors, including pro-inflammatory markers like erythrocyte sedimentation rate (ESR), to perform CVD risk assessment [42-44]. Such integrated risk calculators have demonstrated better CVD risk stratification when compared to traditional CVD risk calculators in non-RA patients [42, 43, 45].

Besides these statistically derived CVD risk calculators, artificial intelligence (AI)-based techniques are also penetrating several medical imaging and risk assessment applications [46-54]. AI-based algorithms such as machine learning (ML) methods provide a better CVD risk assessment when compared with statistically derived conventional risk calculators [51, 55, 56]. So far, AI algorithms have been used for CVD risk assessment in the non-RA population, and their potential still needs to be evaluated in RA cohorts. However, AI is well adapted for RA screening and diagnosis [57-60]. This review provides an insight into how the AI-based algorithms can be used for CVD risk assessment in RA patients. There are three aims of this review: (1) to summarize the pathophysiological pathways that link RA with CVD; (2) to identify several traditional and carotid ultrasound image-based CVD risk calculators for RA patients, and (3) to provide an understanding of the role of artificial intelligence in CVD risk assessment in RA patients.

\section{Search strategy}

Figure 1 shows a flow diagram indicating the search strategy for this narrative review. To write a comprehensive narrative review, it is essential to select at least two credible databases that provide high-quality peer-reviewed articles [61]. This review is the outcome of several searches in the PubMed and Web of Science databases using keywords such as "cardiovascular diseases" AND "risk assessment" AND "rheumatoid arthritis," "carotid atherosclerosis" AND "rheumatoid arthritis," "non-invasive imaging" AND "rheumatoid arthritis," "carotid ultrasound" AND "rheumatoid arthritis," "carotid intima-media thickness" OR "carotid plaque" AND "inflammatory markers," "carotid atherosclerosis" AND "erythrocyte sedimentation rate" OR " $\mathrm{C}$ reactive protein," "machine learning" AND "rheumatoid arthritis," and "machine learning" AND "cardiovascular risk assessment" AND "rheumatoid arthritis." The availability of all these keywords in the abstract and the full text was investigated to select the relevant articles. Peer-reviewed articles published in the last 10 years were then given priority. Citations from the published articles were also shortlisted for this review. All these articles were subsequently filtered by the expert co-authors to select only those that met the objectives of this review, leading to 120 articles.

\section{Pathophysiology of RA leading to CVD}

The pathophysiological association between RA and CVD can be explained in two stages: (1) the role of traditional risk factors, and (2) direct vascular damage. Inflammation plays a pivotal role in both of these stages [24].

\section{The role of traditional risk factors in the pathophysiology of RA-driven atherosclerotic CVD}

The right-hand panel of Fig. 2 explains the pathophysiological association between RA and CVD via four pathways $[\mathrm{I}(\mathrm{a})-\mathrm{I}(\mathrm{d})]$ governed by traditional risk factors such as hypertension, proatherogenic dyslipidemia, insulin resistance, and obesity. Patients with RA are generally found with pro-inflammatory cytokines such as interleukin (IL) 1, IL-6, and tumor necrosis factor $\alpha$ (TNF- $\alpha$ ) [62]. These pro-inflammatory cytokines are found in the synovium, which triggers a systemic inflammatory response, and may result in damage to the vascular endothelial cells [62]. Nitric oxide (NO) and cyclooxygenase- 1 are two essential components required 


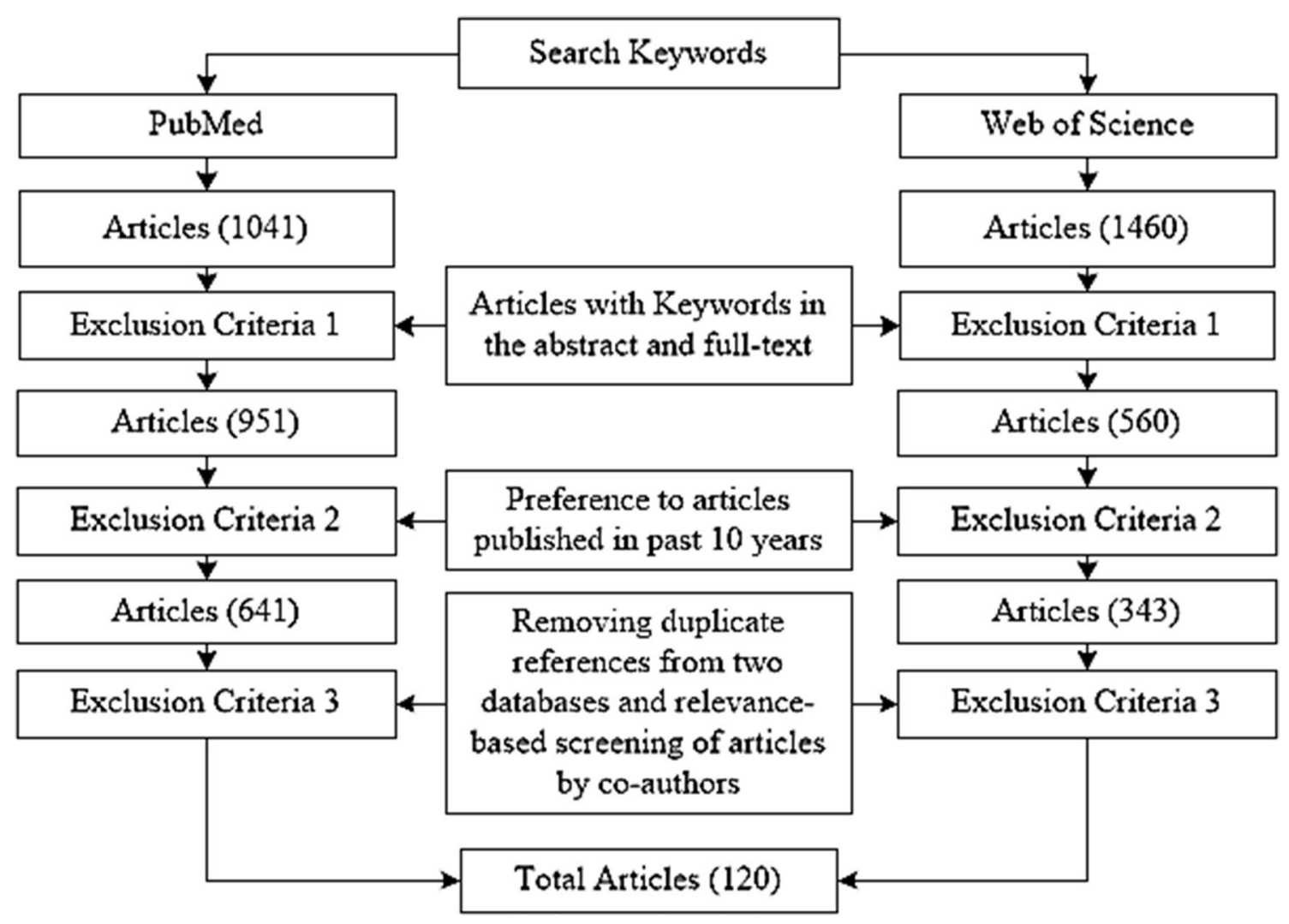

Fig. 1 Flow diagram for the search strategy

to maintain the healthy endothelium, which is inhibited by TNF- $\alpha$ and IL-6, thereby resulting in endothelial cell damage $[23,62]$. Inhibiting endothelial NO leads to arterial stiffness [63] and is further associated with an increase in peripheral vascular resistance (PVR) [64], thus leading to hypertension in RA patients. Additionally, several medications used to treat RA, such as disease-modifying antirheumatic drugs (DMARDs) leflunomide and cyclosporine, glucocorticoids, nonsteroidal anti-inflammatory drugs (NSAIDs), and cyclooxygenase II inhibitors (Cox IBs) may also be involved in the development of hypertension in RA patients $[65,66]$.

Another pathophysiological link between RA and CVD is proatherogenic dyslipidemia [67]. Nearly 55\%-65\% of RA patients have proatherogenic dyslipidemia [68]. In non-RA patients, increased CVD risk is associated with elevated levels of low-density cholesterol (LDL-c), total cholesterol, and reduced high-density lipoprotein cholesterol (HDL-c). However, in RA patients, low levels of total cholesterol (TC), low levels of LDL-c, and suppressed levels of HDL-c have been reported. This condition is known as "the lipid paradox" [14]. Highly suppressed HDL levels in RA patients are "proatherogenic" [14]. Furthermore, RA patients show high atherogenic index levels despite low lipid levels. The atherogenic index is calculated as a ratio of TC: HDL-c, and it may vary according to their levels [14]. Apolipoprotein B (Apo B) is a major apolipoprotein in LDL, and several studies have indicated an increase in the ratio of Apo B: Apo A in RA patients [14]. A combination of low TC, LDL-c, and suppressed HDL-c levels with a high atherogenic index and a high ApoB:ApoA ratio behaves as proatherogenic dyslipidemia [14, 69]. Long-standing proatherogenic dyslipidemia causes atherosclerosis and, eventually, CVD.

Rheumatoid cachexia is another important RA-specific characteristic that increases CVD risk [70]. It is characterized by significantly increased adiposity and reduced muscle mass while one maintains their bodyweight [71]. The pathophysiology [shown in "pathway-I (c)"] behind $R$. cachexia can be explained in two ways: (1) It is characterized by the reduction of muscle mass that is largely due to increased inflammatory cytokines (particularly TNF- $\alpha$ ) by activating the transcriptional nuclear factor-kappa $B$ cells (NF-kB) pathway and promoting the ubiquitin pathway, which causes catabolism/proteolysis (muscle protein breakdown) [72, 73]. (2) Central obesity or abdominal obesity is present in $20-57 \%$ of women and $80-90 \%$ of men. This causes visceral adiposity in RA, which has an additional adverse impact on CVD [74]. On the other hand, increased adiposity also induces the production of inflammatory cytokines in RA, which further worsens this 


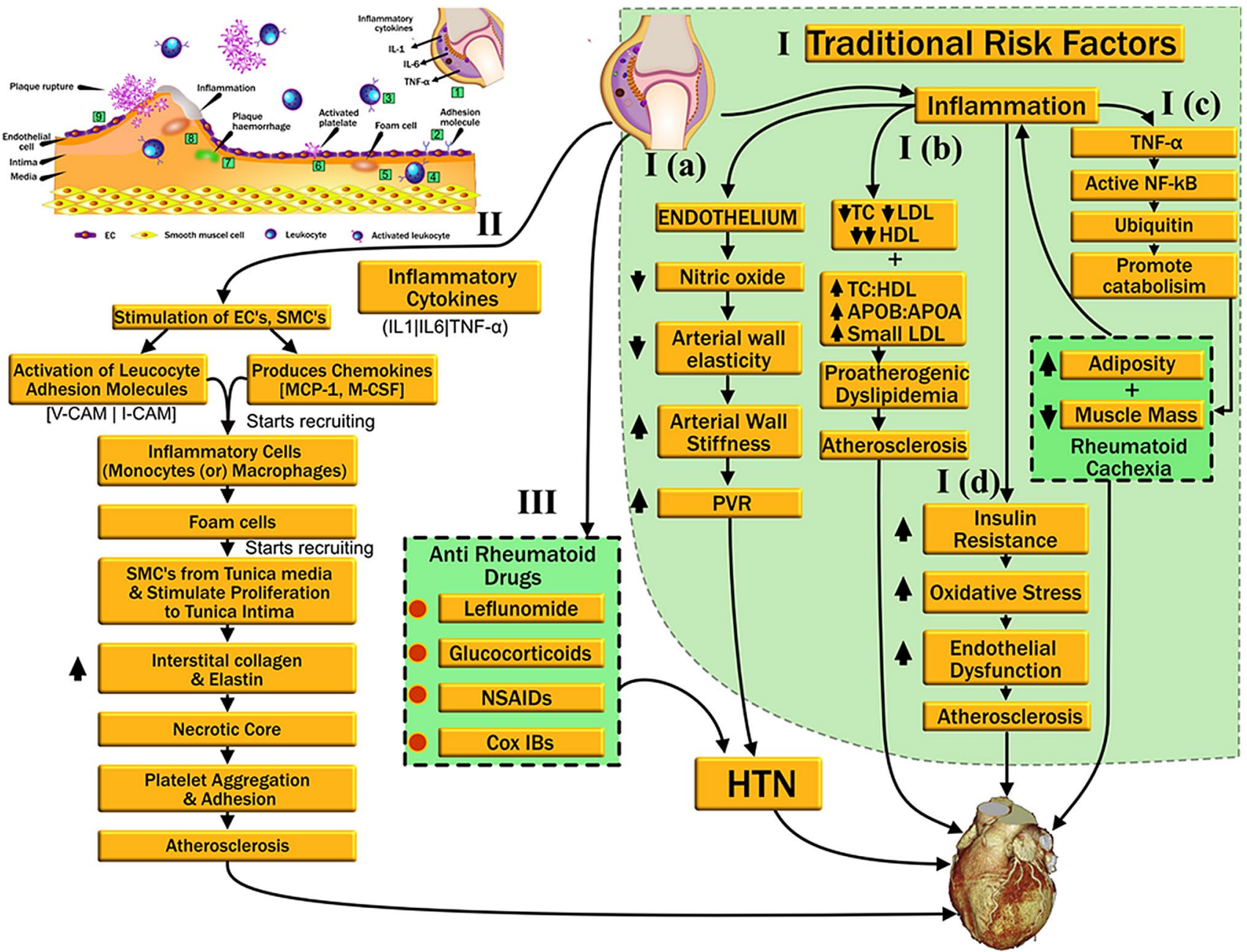

Fig. 2 Pathophysiological association between rheumatoid arthritis and cardiovascular disease. ILI interleukin 1, IL6 interleukin 6, $T N F-\alpha$ tumor necrosis factor $\alpha, E C$ endothelial cells, SMC smooth muscle cells, $M C P-1$ monocyte chemoattractant protein 1, $M$-CSF macrophage colony-stimulating factor, $V$-CAM vascular cell adhesion molecule, I-CAM intercellular adhesion molecule, NSAIDs nonsteroi- dal anti-inflammatory drugs, Cox-IBs cyclo-oxygenase inhibitors, $H T N$ hypertension, $P V R$ peripheral vascular resistance, TC total cholesterol, $H D L$ high-density lipoprotein, $L D L$ low-density lipoprotein, $A P O B$ apolipoprotein $\mathrm{B}, A P O A$ apolipoprotein $\mathrm{A}, N F-k B$ nuclear factor-kappa B cells

\section{Progression of atherosclerosis and direct vessel damage in RA}

In RA, the activation of T-cells and mast cells increases the production of pro-inflammatory cytokines such as IL-1, IL-6, and TNF- $\alpha$. These pro-inflammatory cytokines stimulate endothelial cells (ECs) and smooth muscle cells (SMCs) in subendothelium [80] (1) by expressing cell adhesion molecules such as vascular cell adhesion molecule 1 (VCAM) and the "intercellular adhesion molecule" (ICAM) [80] and (2) by producing chemokines, including monocyte chemoattractant protein $(\mathrm{MCP})$ and macrophage colony-stimulating factor (M-CSF). The activation of endothelial cells allows the migration of LDL-c into the sub-endothelial layer, where 
it becomes oxidized and triggers the inflammatory response for the recruitment of immune cells such as $\mathrm{T}$ lymphocytes and monocytes in the intimal layer. Once they enter the intimal layer, monocytes are transformed into macrophages, and they then take up the oxidized LDL-c to become foam cells. The completion of this complex process then leads to the formation of atherosclerotic plaque. Macrophages also trigger the migration of smooth muscle cells from tunica media to tunica intima and initiate their proliferation. The SMCs form a thin fibrous cap to prevent the encroachment of atherosclerotic plaque towards the lumen. However, over time, pro-inflammatory cytokines, enzymes, and free radicals cause fibrous cap erosion and make the plaque vulnerable for rupture. The amplification of the inflammatory response results in the acceleration of plaque formation, eventually leading to plaque rupture and thrombotic events, which damage the blood vessels. Pathway II of Fig. 2 represents this process.

\section{Current conventional CVD risk prediction models for RA}

Over the last decade, several CVD risk assessment calculators have been developed, very few of which are recommended by the cardiovascular risk management guidelines $[9,81,82]$. Some standard cardiovascular risk prediction algorithms are the Framingham risk score (FRS) [7], Systematic Coronary Risk Evaluation (SCORE) [8], American College of Cardiology/American Heart Association (ACC/ AHA) risk score [9], World Health Organization (WHO) risk charts [83], and Reynolds's risk score (RRS) [17]. These risk calculators use traditional risk factors such as patient demographics (age, gender, ethnicity), blood biomarkers (low-density lipoprotein cholesterol, high-density lipoprotein cholesterol, and total cholesterol), behavioral markers (smoking and alcohol consumption), and physiological markers (height, weight, body mass index). All these risk calculators were initially developed for non-RA populations; therefore, when used in RA cohorts, CVD risk is substantially underestimated [10-12]. The use of traditional risk factors alone (while not considering RA-specific inflammatory markers) could be another reason for such underestimation. However, RRS included an RA-specific inflammatory marker called "high sensitivity C-reactive protein" (hs-CRP) [84] for CVD risk prediction but did not report any significant improvement in the CVD risk assessment [11]. Rajagopalan et al. [85] also reported a small improvement in area under the curve $(+0.006$ in females and +0.004 in males) when $\mathrm{C}$ reactive protein $(\mathrm{CRP})$ or erythrocyte sedimentation rate (ESR) was added to the FRS.

Over the past few years, several efforts have been made to improve the cardiovascular risk assessment in RA patients.
The EULAR guidelines recommended the use of a modified SCORE (mSCORE) in RA patients positive with rheumatoid factor (RF) or anticitrullinated protein antibodies (ACPA) and RA duration of more than 10 years $[16,86]$. Cox et al. $[19,20]$ developed the QRISK2 and QRISK3 algorithms, which use the presence of RA as a CVD risk predictor (hazard ratio $=1.23,95 \%$ confidence interval $1.19-1.28$ ). Solomon et al. [18] also developed an RA-specific CVD risk calculator (called expanded risk score or ERS) by including RA-specific biomarkers [such as disease activity, disease duration, a modified health assessment questionnaire (HAQ) disability index, and daily prednisone use] with the traditional biomarkers used in the Cox-based model. The authors reported an improvement of $\sim 4.8 \%$ in c-index when validating the risk score on the reserved dataset. Recently, Curtis et al. [87] also proposed a CVD risk prediction tool for RA patients by combining conventional and RA-specific risk factors. The authors predicted the risk of composite CVD events such as MI, stroke, and death during the follow-up period of 3 years. The area under the curve (AUC) for cardiovascular risk stratification for this model was 0.70 .

All these RA-specific CVD risk scores reported a better risk assessment on the proprietary databases. Still, when compared with other risk calculators in different RA cohorts, these calculators have demonstrated mixed results [10-12]. Crowson et al. [11] reported an underestimation of CVD risk by FRS and RRS in 525 RA patients. The observed risk was twice the predicted risk. Furthermore, the authors did not report any improvement in cardiovascular risk prediction when CRP was added to their model. Arts et al. [10] investigated the roles of SCORE, FRS, RRS, and QRISK2 in 1050 RA patients. Out of these four models, SCORE, FRS, and RRS underestimated CVD risk in RA patients, whereas, the QRISK2 reported an overestimation. The AUC ranged between 0.78 and 0.80 for the four risk models. A similar study by Arts et al. [12] investigated the performance of the original, recalibrated, and improved version of SCORE calculators to predict the CVD risk in $1016 \mathrm{RA}$ patients. The AUC values for these scores were 0.78 (95\% CI 0.74-0.82), $0.78(0.74-0.83)$, and $0.80(0.75-0.84)$. All these three scores underestimated the CVD risk in RA patients. In short, even after the SCORE was redesigned using the RA-based risk factors, it did not result in an adequate CVD risk assessment. In another study by Crowson et al. [21] of 5638 RA patients, a CVD-risk prediction model was developed that reported better performance $(\mathrm{AUC}=0.71)$ compared with conventional risk calculators such as FRS $(\mathrm{AUC}=0.71)$, ACC/AHA $(\mathrm{AUC}=0.72)$, SCORE $(\mathrm{AUC}=0.70)$, and QRISK2 (AUC $=0.72$ ). Furthermore, conventional risk calculators either overestimated or underestimated CVD risk in RA patients. Wahlin et al. [88] compared the expanded risk score, ACC/AHA risk score, and a modified version of ACC/ AHA with a multiplier of 1.5 for a CVD risk assessment of 
665 RA patients. The authors also reported an underestimation of CVD risk by all calculators. However, the discrimination ability was slightly better, since AUC for ERS-RA risk was 0.78 compared to AUC of 0.98 for two variants of ACC/AHA.

The overall trend of all these risk prediction algorithms, developed for general and RA cohorts, indicates a "poor CVD risk assessment" in patients with RA. One possible reason for such poor performance is the paradoxical behavior of some of the risk factors such as lipids and body mass index. Another potential reason for this outcome is the inclusion of risk factors that do not provide complete information about the CVD risk profile in RA patients [89]. Corrales et al. [89] indicated a high prevalence of carotid atherosclerosis plaque in patients with low-CVD risk. This observation demonstrated the limited ability of conventional risk factor-based algorithms to improve the CVD risk assessment process, which may be improved using imaging modalities. Therefore, there is still room to develop more accurate, automated, and reliable risk calculators for RA patients by exploring and including nontraditional risk factors such as genetic biomarkers, inflammatory biomarkers, or image-based atherosclerotic plaque phenotypes in the risk prediction algorithm.

\section{Carotid ultrasound atherosclerosis imaging for CVD risk assessment in RA patients}

Imaging modalities are becoming essential for the visualization of atherosclerotic plaque and CVD risk assessment in RA patients [90]. Non-invasive imaging modalities such as computed tomography, magnetic resonance imaging, ultrasound, and positron emission tomography are currently used to assess carotid atherosclerosis in RA patients [26]. MRI is used to measure the plaque composition, including calcification, lipid-rich necrotic core, and fibrous cap thickness [26]. Computed tomography is generally used to determine carotid artery stenosis [27]. F-fludeoxyglucose-positron emission tomography (FDG-PET) is a nuclear imaging modality that quantifies the inflammation in carotid atherosclerotic plaque [91]. Non-invasive carotid ultrasound is a commonly adopted imaging modality that can capture morphological variations in the atherosclerotic plaque quantified using (1) carotid intima-media thickness (cIMT), (2) carotid intima-media thickness variability (IMTV), and (3) plaque area [30]. When compared with other non-invasive counterparts, carotid ultrasound is less expensive and easier to use $[30,92]$. Therefore, the scope of this review is restricted to the use of carotid ultrasound for CVD risk assessment in RA patients. The automated cIMT and carotid PA are considered surrogate markers of coronary artery disease and widely used for CVD/stroke risk assessment [31-34].
Several studies have shown a high prevalence of increased cIMT and carotid plaque in RA patients [39-41]. Studies have also demonstrated the significant association between these carotid atherosclerosis biomarkers and RA-specific markers of inflammation, such as ESR, CRP, and IL-6 [35-38]. Table 1 provides some of such studies that link both carotid atherosclerosis and RA, using two sets of biomarkers (i.e., image-based phenotypes and inflammatory biomarkers). One common observation from these studies is that patients with RA show an elevated cIMT and carotid plaque area compared with non-RA cohorts (row R2-R4 of Table 1) [39, 40, 93]. This association between carotid atherosclerosis and RA also seems independent of the three carotid artery segments (common carotid artery, carotid bulb, and internal carotid artery) from where the cIMT or plaque was measured [40,93]. However, several studies have reported more aggressive atherosclerotic plaque formation in the carotid bulb segment when compared to other arterial segments [94]. The higher plaque prevalence in the carotid bulb is a consequence of turbulent blood flow and reduced shear stress, which leads to endothelial dysfunction [95, 96]. This observation of higher plaque in a bulb has also been confirmed in RA patients [40]. Figure 3 shows carotid ultrasound scans for RA (Fig. 3a, b) and non-RA patients (Fig. 3c, d). The left-hand side panel of Fig. 3a, c shows the raw carotid ultrasound scans measured using a B-mode ultrasound scanner.

Similarly, the right-hand side panels of Fig. 3b, d show the processed scans tracking morphological variations in the carotid atherosclerotic plaque for the quantification of cIMT and plaque area. The cIMT and plaque area are both greater in RA patients than in non-RA patients.

Another important observation from Table 1 is the significant association between carotid atherosclerotic biomarkers and RA-specific inflammatory markers, such as ESR, CRP, and IL-6 [37, 97]. ESR is a relatively inexpensive measure of inflammation in RA patients - therefore, several studies have used ESR for CVD risk assessment [98-100]. Some of such studies are listed in Table 2. All these studies indicated a substantially higher CVD event rate in patients with elevated ESR levels. Besides ESR, studies have also suggested the use of other popular RA-specific inflammatory markers such as CRP, or hsCRP, and IL-6 for the improvement in the CVD risk assessment [37, 85, 101, 102]. Furthermore, these RA-specific inflammatory markers are also associated with the annual progression of cIMT [38, 97, 103-105], which is a prominent surrogate marker of cardiovascular events. In a study with 30 RA patients, Kaseem et al. [37] demonstrated the association of ESR, CRP, and IL-6 with carotid atherosclerosis, with significant odds ratios $(p<0.05)$ of 1.50 , 1.90 , and 1.80 , respectively.

The broad usage of carotid ultrasound-based phenotypes and their significant association with RA-specific 


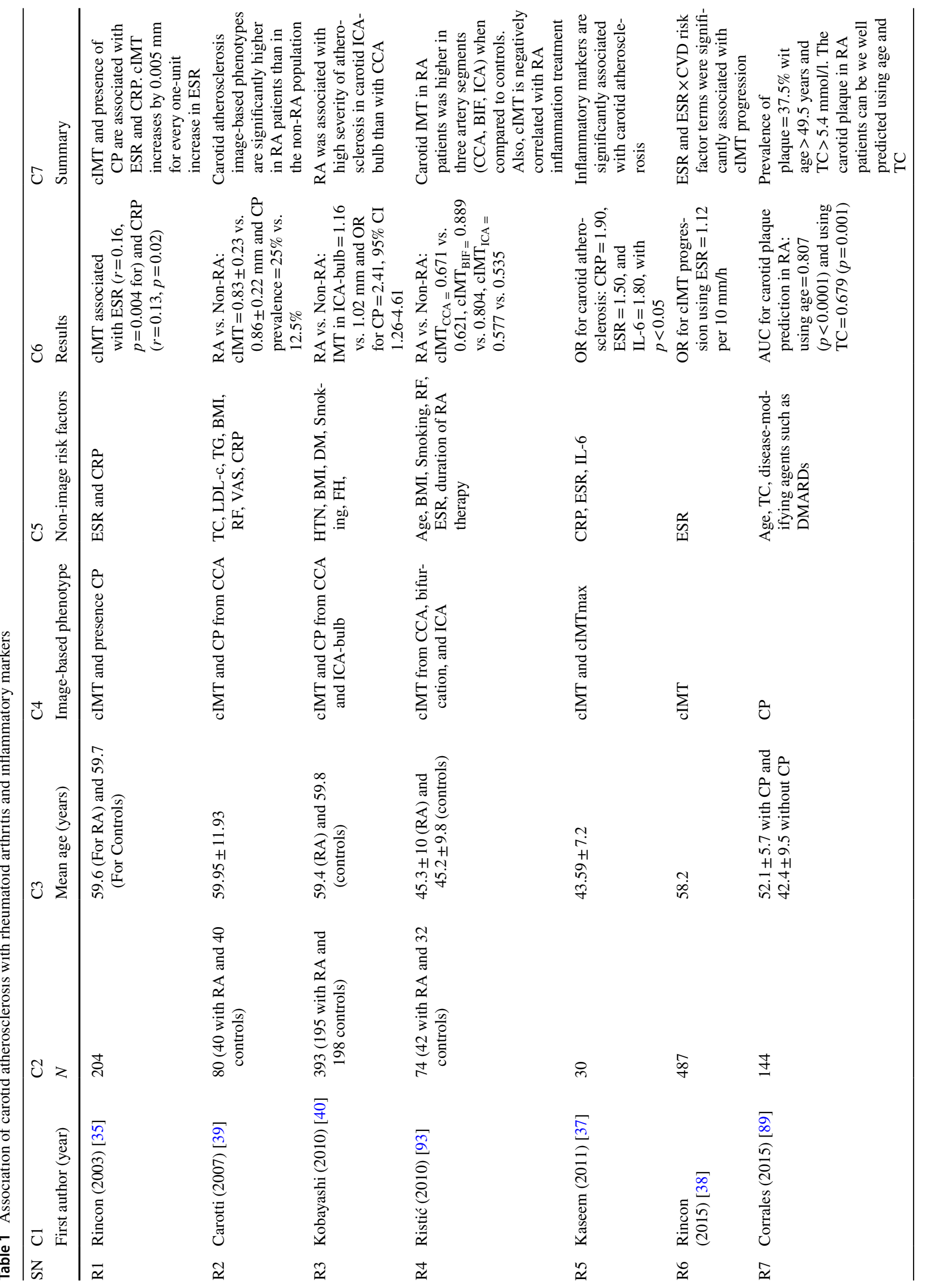




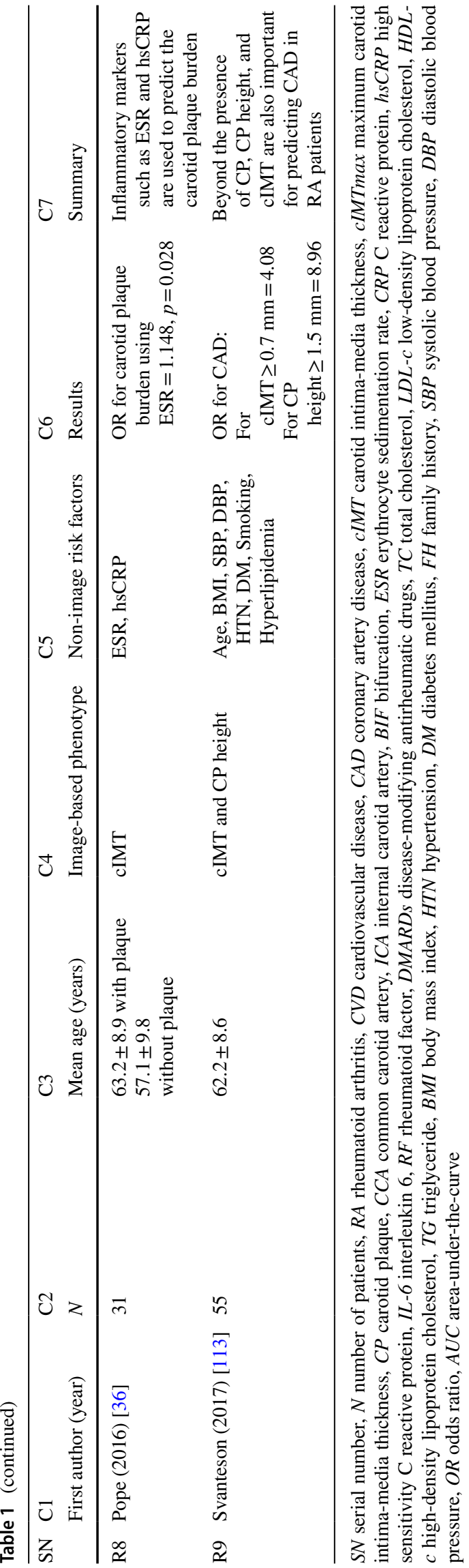

inflammatory markers has also enabled their inclusion in the CVD risk prediction calculators [42, 43, 54, 106]. Recently, several CVD/stroke risk prediction models have been developed that have combined the effect of conventional risk factors and the automated carotid atherosclerosis biomarkers $[42,43]$. These risk prediction models reported a better performance in identifying high CVD risk patients compared with current standard-of-care risk calculators. However, such so-called integrated risk prediction models were developed for the general population. They were based on the annual progression rates of carotid atherosclerotic biomarkers and conventional risk factors [42-44]. Therefore, given the progression rates of cIMT and PA due to the RAspecific inflammatory markers, such models can be updated and might be useful for CVD risk assessment in RA patients.

\section{Artificial intelligence in CVD/stroke risk assessment}

Artificial intelligence (AI) is expeditiously changing the landscape of the global healthcare system and assisting the healthcare workforce in clinical decision-making [107]. Machine learning (ML) and deep learning (DL) are the two common branches of AI that have broad ranges of applications in almost every medical imaging sector (e.g., classification and plaque characterization for stroke risk assessment [47], thyroid cancer characterization [48], liver cancer diagnosis [49], prostate cancer diagnosis, ovarian cancer diagnosis [53], lung cancer detection [108], brain tumor classification [50], and heart disease prediction and disease classification $[51,52,54])$. During the recent global pandemic of coronavirus diseases 2019, AI is providing promising results in the diagnosis of patients with the help of several imaging techniques such as computed tomography [109] and X-rays [110].

Since this review is on CVD/stroke risk assessment, we have summarized several studies that have used ML-based algorithms for CVD/stroke risk assessment (Table 3). All of these studies follow a supervised learning approach in which the ML-based classifier is trained to identify the correct output labels using input risk factors or features and predefined gold standards or labels. Figure 4 shows the generalized framework of supervised ML-based CVD risk assessment. In the case of CVD risk assessment, the gold standard can be (1) the primary endpoints such as presence or absence of cardiovascular events, or (2) surrogate endpoints such as CIMT, PA, and CAC score, or a combination of these risk factors [51, 52, 54]. Several types of input features can be used to train the AI-based algorithms. They can be traditional risk factors, image-based phenotypes, grayscale image features, or statistically derived features. Once the offline ML classifier is trained using these features and gold 
Fig. 3 Carotid ultrasound image of the common carotid artery for control patients

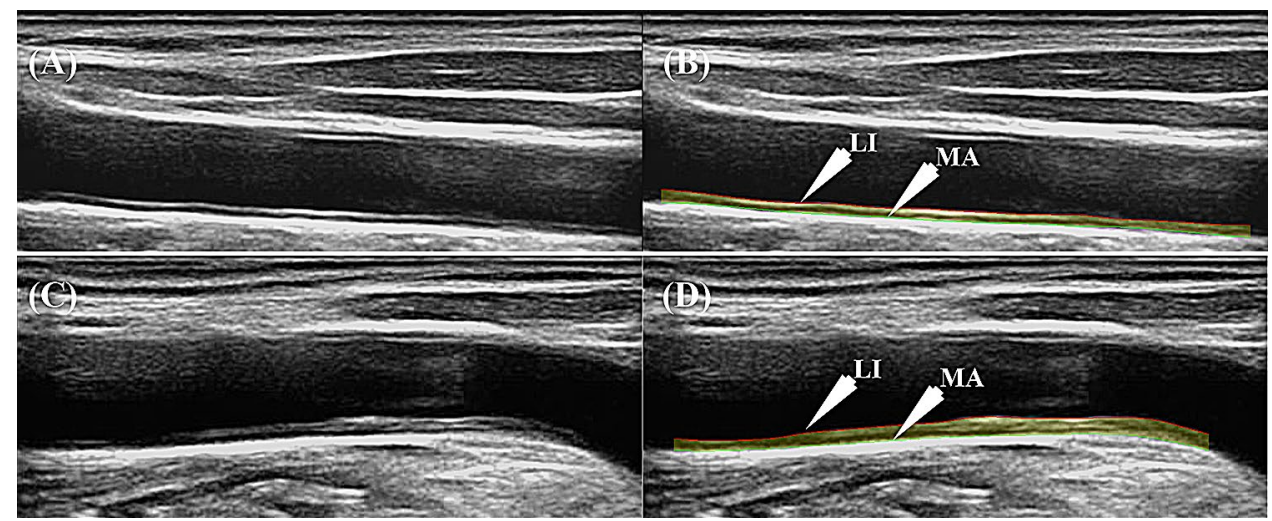

standard, its coefficients are then used in the online ML system to predict the out risk labels. Online ML systems do not require a gold standard to make the final risk classification. All the studies provided in Table 3 used this approach for CVD risk assessment. Unlike ML-based algorithms, DLbased models, such as convolutional neural networks, do not require input features beforehand. Instead, such algorithms automatically learn their offline coefficients from the input image datasets [111].

Currently, AI-based techniques are used in the diagnosis of RA [57], the identification of RA disease severity [58], the classification of several RA synovial tissues [59], and mortality prediction due to RA [60]. Although ML-based algorithms are used in the RA field, no efforts have been made to assess the CVD risk in RA patients using such automated intelligence-based paradigms. ML-based algorithms have been used to perform CVD risk assessments in non-RA populations and reported a better performance in identifying high-risk CVD patients when compared with the current standard of care conventional risk calculators $[51,55,56]$. Patients with RA experience more atherosclerotic plaque in the carotid artery, which might lead to cardiovascular events [39-41]. In recent years several studies have demonstrated a better stroke risk assessment using ML-based strategies [29] and DL-based strategies [112]. Besides all these studies, attempts can be made to develop more accurate CVD risk prediction tools for RA patients using AI techniques. Figure 5 conceptualizes several components required for CVD risk assessment in RA patients. The AI-based CVD risk assessment for RA patients can be made possible by combining several types of risk factors, such as patients' demographics, physiological parameters, behavioral risk factors, image-based phenotypes, and (most importantly) RA-specific inflammatory markers. This combined set of features can be used as inputs along with the gold standard to identify what CVD risk category RA patients belong to. As such, both ML and DL-based systems can be employed to performed CVD risk assessment in patients. Because of the significant association between carotid atherosclerosis and RA, researchers can conduct a pilot study with cIMT and plaque areas as the surrogate markers for CVD risk assessment.

\section{Summary}

In this review, we provided several pathophysiological pathways that highlight the role of cardiovascular and inflammatory risk factors in the progression of atherosclerosis and heart injury in RA patients. Furthermore, we also indicated an unmet need to look for new biomarkers to achieve a more accurate cardiovascular risk assessment in RA patients. Specifically, carotid ultrasound is a non-invasive and economical technique for preventive screening applications. The carotid atherosclerotic image-based biomarkers such as cIMT and plaque have a significant association with RA-specific inflammatory markers. Most of the current statistically derived cardiovascular risk calculators, developed for both RA and non-RA cohorts, either underestimate or overestimate the CVD risk in RA patients. Even after the inclusion of RA-specific inflammatory markers such as CRP, risk calculators reported little improvement in risk prediction. The accuracy of risk assessment can be improved using AI techniques. AI techniques are currently used for RA screening and not for CVD risk assessment in RA patients. However, they reported promising results of CVD risk assessment in non-RA cohorts. Thus, we believe that the development of AI-driven risk prediction models by combining traditional, image-based, and inflammatory risk factors is warranted to improve the CVD risk assessment in RA patients. 


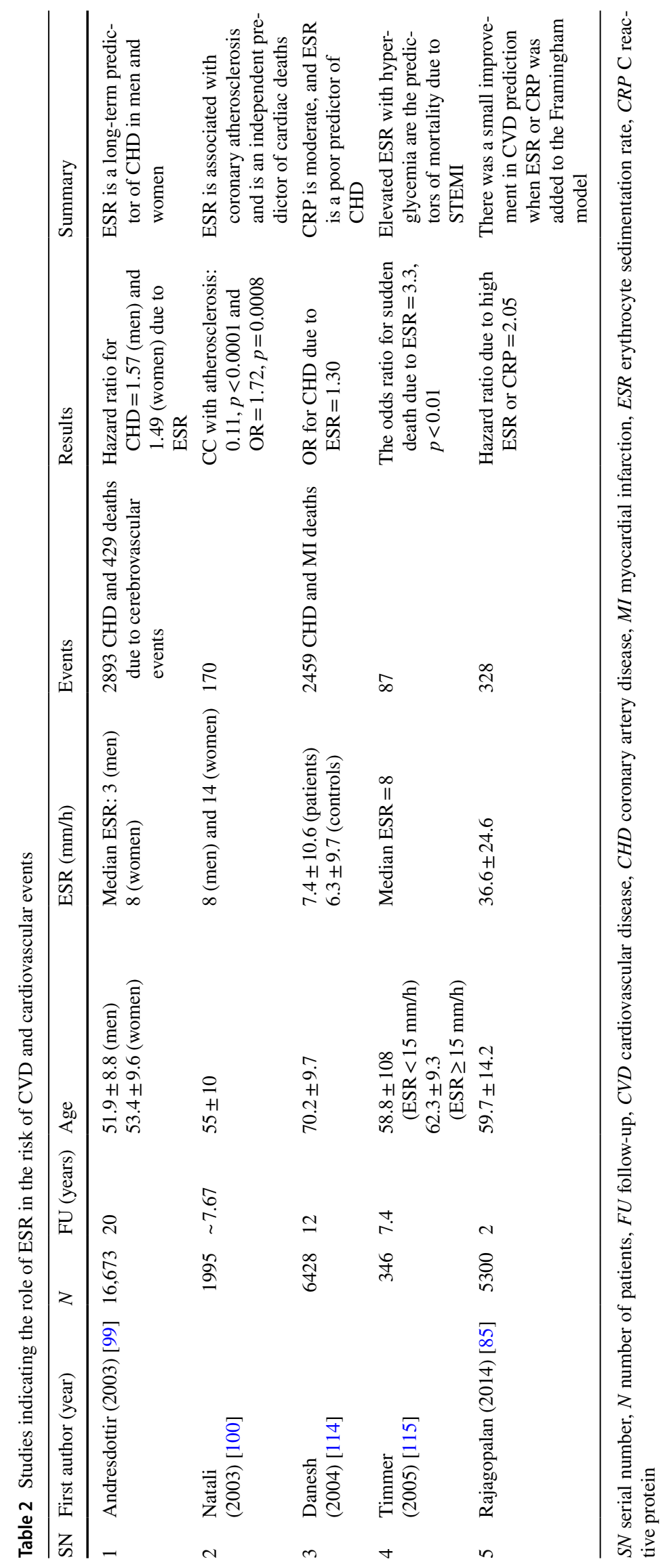




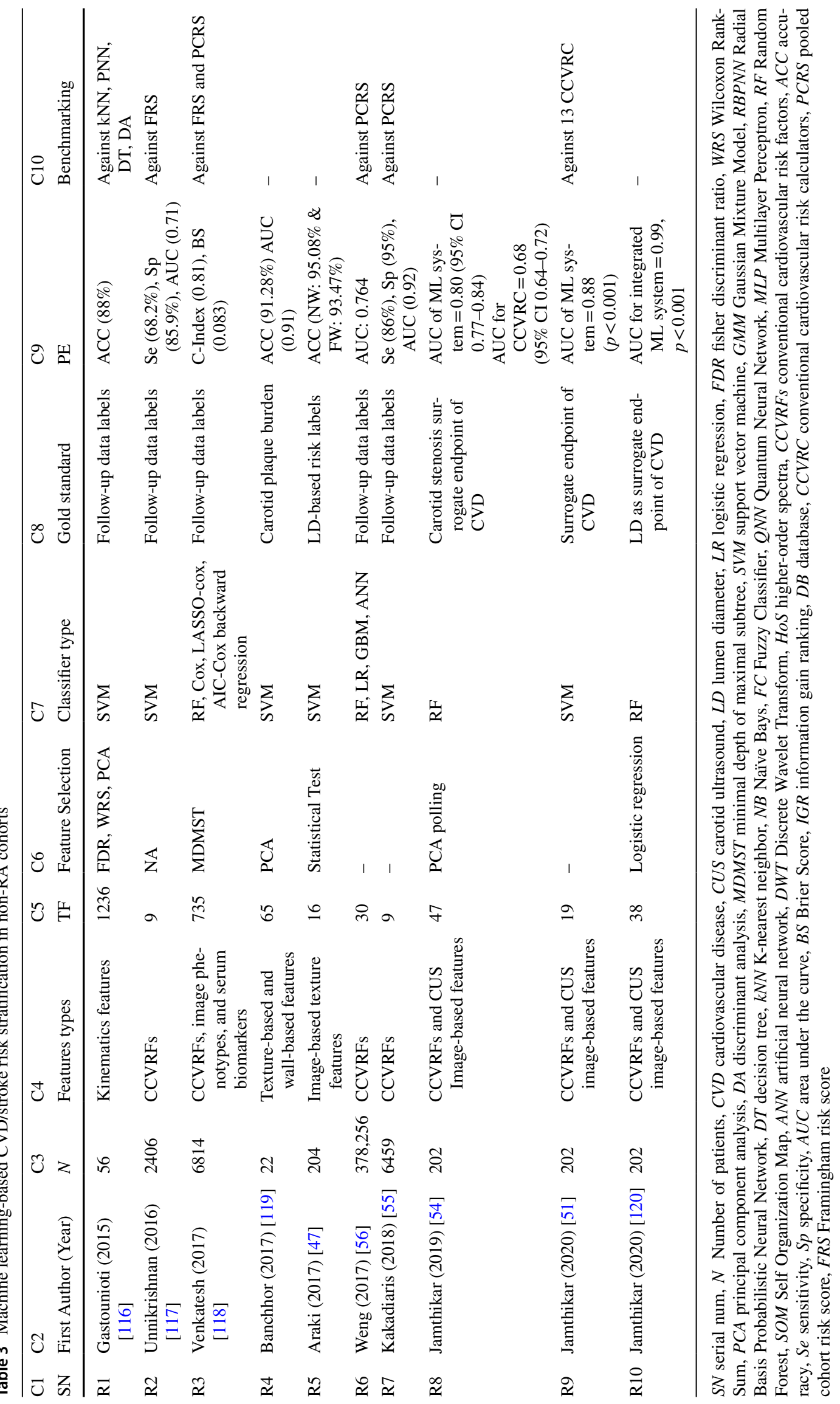




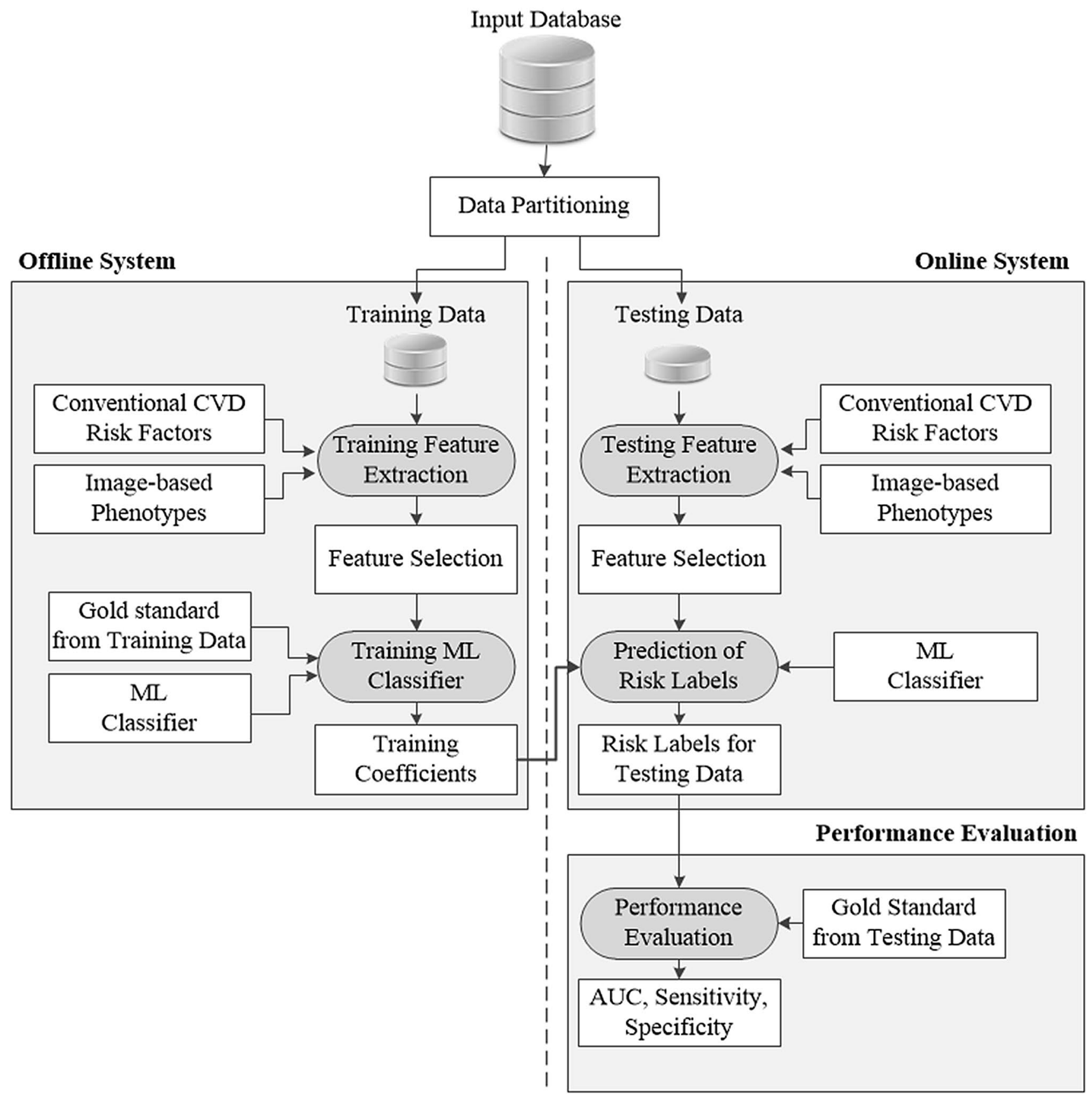

Fig. 4 The generalized framework of supervised ML-based CVD risk assessment system. $C V D$ cardiovascular disease, $M L$ machine learning, $A U C$ area under the curve 


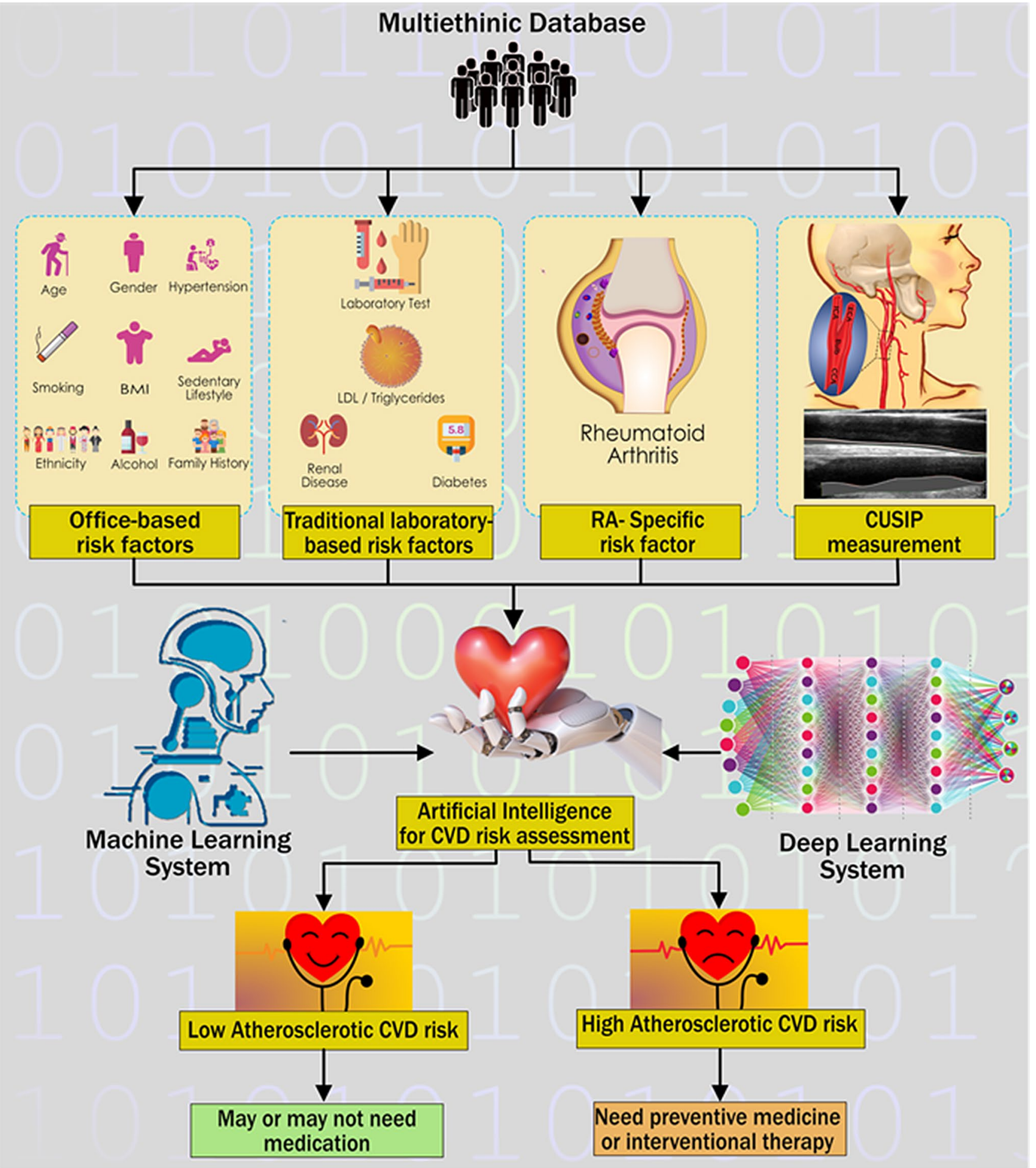

Fig. 5 AI framework for CVD risk assessment in RA patients. $B M I$ mody mass index, $L D L$ low density lipoprotein, $C V D$ cardiovascular disease, $R A$ rheumatoid arthritis, CUSIP carotid ultrasound image-based phenotypes

Author contributions ADJ: Design of the manuscript, proofreading many iterations, researching PubMed and other research sites for article search. DG, PPS, AP, VV: Resources, imaging contribution and proofreading the manuscript. AP: Design of the rheumatoid arthritis component of the manuscript, proofreading many iterations, researching PubMed and other research sites for article search. AJ: Proofreading 
and guidance of cardiology components of the manuscript. NNK: The vision of cardiac risk assessment and proofreading the manuscript, final approval of the manuscript. LS: Design and support of radiology components such as CT and carotid ultrasound. SM: Proofreading and guidance of cardiology imaging components of the manuscript. JRL, GP, MM, AS, VR: Proofreading and guidance of cardiology and vascular components. GDK: Design and solid proofreading of the manuscript, especially the rheumatology component, revising it critically for important intellectual content, and final approval of the manuscript. RK: Vascular tissue characterization and proofreading of the manuscript. JSS: Principal Investigator-design, proofreading of the manuscript and management.

\section{Compliance with ethical standards}

Conflict of interest The author(s) declare that they have no competing interests.

\section{References}

1. Smolen JS, Aletaha D, McInnes IB (2006) Rheumatoid arthritis. Lancet 388(10055):2023-2038. https://doi.org/10.1016/s0140 $-6736(16) 30173-8$

2. Cojocaru M, Cojocaru IM, Silosi I, Vrabie CD, Tanasescu R (2010) Extra-articular manifestations in rheumatoid arthritis. Maedica 5(4):286

3. Cross M, Smith E, Hoy D, Carmona L, Wolfe F, Vos T, Williams B, Gabriel S, Lassere M, Johns N (2014) The global burden of rheumatoid arthritis: estimates from the global burden of disease 2010 study. Ann Rheum Dis 73(7):1316-1322

4. van Vollenhoven RF (2009) Sex differences in rheumatoid arthritis: more than meets the eye. BMC Med 7(1):12

5. Crowson CS, Liao KP, Davis JM III, Solomon DH, Matteson EL, Knutson KL, Hlatky MA, Gabriel SE (2013) Rheumatoid arthritis and cardiovascular disease. Am Heart J 166(4):622-628 (e621)

6. del Rincón ID, Williams K, Stern MP, Freeman GL, Escalante A (2001) High incidence of cardiovascular events in a rheumatoid arthritis cohort not explained by traditional cardiac risk factors. Arthritis Rheum 44(12):2737-2745. https:// doi.org/10.1002/1529-0131(200112)44:12\%3c2737:aid-art46 0\%3e3.0.co;2-\% 23

7. D'agostino RB, Vasan RS, Pencina MJ, Wolf PA, Cobain M, Massaro JM, Kannel WB (2008) General cardiovascular risk profile for use in primary care: the Framingham Heart Study. Circulation 117(6):743-753

8. Conroy R, Pyörälä K, Ae Fitzgerald, Sans S, Menotti A, De Backer G, De Bacquer D, Ducimetiere P, Jousilahti P, Keil U (2003) Estimation of ten-year risk of fatal cardiovascular disease in Europe: the SCORE project. Eur Heart J 24(11):987-1003

9. Goff DC, Lloyd-Jones DM, Bennett G, Coady S, D'agostino RB, Gibbons R, Greenland P, Lackland DT, Levy D, O'donnell CJ (2014) 2013 ACC/AHA guideline on the assessment of cardiovascular risk: a report of the American College of Cardiology/ American Heart Association Task Force on Practice Guidelines. J Am Coll Cardiol 63(25 Part B):2935-2959

10. Arts E, Popa C, Den Broeder A, Semb A, Toms T, Kitas G, Van Riel P, Fransen J (2014) Performance of four current risk algorithms in predicting cardiovascular events in patients with early rheumatoid arthritis. Ann Rheum Dis 74:668-74

11. Crowson CS, Matteson EL, Roger VL, Therneau TM, Gabriel SE (2012) Usefulness of risk scores to estimate the risk of cardiovascular disease in patients with rheumatoid arthritis. Am J Cardiol 110(3):420-424

12. Arts E, Popa C, Den Broeder A, Donders R, Sandoo A, Toms T, Rollefstad S, Ikdahl E, Semb A, Kitas G (2015) Prediction of cardiovascular risk in rheumatoid arthritis: performance of original and adapted SCORE algorithms. Ann Rheum Dis 75:674-80

13. Escalante A, Haas RW, Del Rincón I (2005) Paradoxical effect of body mass index on survival in rheumatoid arthritis: role of comorbidity and systemic inflammation. Arch Intern Med 165(14):1624-1629

14. Urruela MA, Suarez-Almazor ME (2012) Lipid paradox in rheumatoid arthritis: changes with rheumatoid arthritis therapies. Curr Rheumatol Rep 14(5):428-437

15. Agca R, Heslinga SC, Rollefstad S, Heslinga M, McInnes IB, Peters MJL, Kvien TK, Dougados M, Radner H, Atzeni F, Primdahl J, Södergren A, Wallberg Jonsson S, van Rompay J, Zabalan C, Pedersen TR, Jacobsson L, de Vlam K, GonzalezGay MA, Semb AG, Kitas GD, Smulders YM, Szekanecz Z, Sattar N, Symmons DPM, Nurmohamed MT (2016) EULAR recommendations for cardiovascular disease risk management in patients with rheumatoid arthritis and other forms of inflammatory joint disorders: 2015/2016 update. Ann Rheum Dis. https:// doi.org/10.1136/annrheumdis-2016-209775

16. Peters MJ, Symmons D, McCarey D, Dijkmans B, Nicola P, Kvien T, McInnes I, Haentzschel H, Gonzalez-Gay M, Provan S (2010) EULAR evidence-based recommendations for cardiovascular risk management in patients with rheumatoid arthritis and other forms of inflammatory arthritis. Ann Rheum Dis 69(2):325-331

17. Ridker PM, Buring JE, Rifai N, Cook NR (2007) Development and validation of improved algorithms for the assessment of global cardiovascular risk in women: the Reynolds Risk Score. JAMA 297(6):611-619

18. Solomon D, Greenberg J, Curtis J, Liu M, Farkouh M, Tsao P, Kremer J, Etzel CJ (2015) Derivation and internal validation of an expanded cardiovascular risk prediction score for rheumatoid arthritis: a Consortium of Rheumatology Researchers of North America Registry Study. Arthritis Rheumatol 67(8):1995-2003

19. Hippisley-Cox J, Coupland C, Brindle P (2017) Development and validation of QRISK3 risk prediction algorithms to estimate future risk of cardiovascular disease: prospective cohort study. BMJ 357:1-12. https://doi.org/10.1136/bmj.j2099. https://qrisk .org/three

20. Hippisley-Cox J, Coupland C, Vinogradova Y, Robson J, Minhas R, Sheikh A, Brindle P (2008) Predicting cardiovascular risk in England and Wales: prospective derivation and validation of QRISK2. BMJ 336(7659):1475-1482

21. Crowson CS, Rollefstad S, Kitas GD, Van Riel PL, Gabriel SE, Semb AG (2017) Challenges of developing a cardiovascular risk calculator for patients with rheumatoid arthritis. PLoS One 12(3): 0174656

22. Crowson CS, Gabriel SE, Semb AG, van Riel PL, Karpouzas G, Dessein PH, Hitchon C, Pascual-Ramos V, Kitas GD, Arthritis AT-ACCfR (2017) Rheumatoid arthritis-specific cardiovascular risk scores are not superior to general risk scores: a validation analysis of patients from seven countries. Rheumatology 56(7):1102-1110

23. Khanna NN, Jamthikar AD, Gupta D, Piga M, Saba L, Carcassi C, Giannopoulos AA, Nicolaides A, Laird JR, Suri HS, Mavrogeni S, Protogerou AD, Sfikakis P, Kitas GD, Suri JS (2019) Rheumatoid arthritis: atherosclerosis imaging and cardiovascular risk assessment using machine and deep learning-based tissue characterization. Curr Atheroscler Rep 21(2):7. https://doi. org/10.1007/s11883-019-0766-X 
24. Libby P (2008) Role of inflammation in atherosclerosis associated with rheumatoid arthritis. Am J Med 121(10):S21-S31

25. Gasparyan AY, Stavropoulos-Kalinoglou A, Mikhailidis DP, Toms TE, Douglas KM, Kitas GD (2010) The rationale for comparative studies of accelerated atherosclerosis in rheumatic diseases. Curr Vasc Pharmacol 8(4):437-449. https://doi. org/10.2174/157016110791330852

26. Skeoch S, Cristinacce PH, Williams H, Pemberton P, Xu D, Sun J, James J, Yuan C, Hatsukami T, Hockings P (2017) Imaging atherosclerosis in rheumatoid arthritis: evidence for increased prevalence, altered phenotype and a link between systemic and localised plaque inflammation. Sci Rep 7(1):1-12

27. Koelemay MJ, Nederkoorn PJ, Reitsma JB, Majoie CB (2004) Systematic review of computed tomographic angiography for assessment of carotid artery disease. Stroke 35(10):2306-2312

28. Boi A, Jamthikar AD, Saba L, Gupta D, Sharma A, Loi B, Laird JR, Khanna NN, Suri JS (2018) A survey on coronary atherosclerotic plaque tissue characterization in intravascular optical coherence tomography. Curr Atheroscler Rep 20(7):33

29. Jamthikar A, Gupta D, Khanna NN, Araki T, Saba L, Nicolaides A, Sharma A, Omerzu T, Suri HS, Gupta A, Mavrogeni S, Turk M, Laird JR, Protogerou AD, Sfikakis P, Kitas GD, Viswanathan V, Pareek G, Miner M, Suri JS (2019) A special report on changing trends in preventive stroke/cardiovascular risk assessment via B-mode ultrasonography. Curr Atheroscler Rep 21(7):25

30. Saba L, Jamthikar A, Gupta D, Khanna NN, Viskovic K, Suri HS, Gupta A, Mavrogeni S, Turk M, Laird JR, Pareek G, Miner M, Sfikakis P, Protogerou A, Kitas GD, Viswanathan V, Nicolaides A, Bhatt D, Suri JS (2019) Global perspective on carotid intimamedia thickness and plaque: should the current measurement guidelines be revisited? Int Angiol 38(6):451-465. https://doi. org/10.23736/s0392-9590.19.04267-6

31. Polak JF, Pencina MJ, Pencina KM, O'Donnell CJ, Wolf PA, D'Agostino RB Sr (2011) Carotid-wall intima-media thickness and cardiovascular events. N Engl J Med 365(3):213-221. https ://doi.org/10.1056/NEJMoa1012592

32. Lorenz MW, Sitzer M, Markus HS, Bots ML, Rosvall M (2007) Prediction of clinical cardiovascular events with carotid intima-media thickness: a systematic review and meta-analysisresponse. Circulation 116(9):318

33. Stein JH, Korcarz CE, Hurst RT, Lonn E, Kendall CB, Mohler ER, Najjar SS, Rembold CM, Post WS (2008) Use of carotid ultrasound to identify subclinical vascular disease and evaluate cardiovascular disease risk: a consensus statement from the American Society of Echocardiography Carotid Intima-Media Thickness Task Force endorsed by the Society for Vascular Medicine. J Am Soc Echocardiogr 21(2):93-111

34. Johri AM, Nambi V, Naqvi TZ, Feinstein SB, Kim ES, Park MM, Becher H, Sillesen H (2020) Recommendations for the assessment of carotid arterial plaque by ultrasound for the characterization of atherosclerosis and evaluation of cardiovascular risk: from the American Society of Echocardiography. J Am Soc Echocardiogr 33:917-933

35. del Rincón I, Williams K, Stern MP, Freeman GL, O'leary DH, Escalante A (2003) Association between carotid atherosclerosis and markers of inflammation in rheumatoid arthritis patients and healthy subjects. Arthritis Rheumatol 48(7):1833-1840

36. Pope JE, Nevskaya T, Barra L, Parraga G (2016) Carotid artery atherosclerosis in patients with active rheumatoid arthritis: predictors of plaque occurrence and progression over 24 weeks. Open Rheumatol J 10:49

37. Kassem E, Ghonimy R, Adel M, El-Sharnoby G (2011) Non traditional risk factors of carotid atherosclerosis in rheumatoid arthritis. Egypt Rheumatol 33(3):113-119
38. Del Rincon I, Polak JF, O'Leary DH, Battafarano DF, Erikson JM, Restrepo JF, Molina E, Escalante A (2015) Systemic inflammation and cardiovascular risk factors predict rapid progression of atherosclerosis in rheumatoid arthritis. Ann Rheum Dis 74(6): 1118-1123

39. Carotti M, Salaffi F, Mangiacotti M, Cerioni A, Giuseppetti G, Grassi W (2007) Atherosclerosis in rheumatoid arthtritis: the role of high-resolution B mode ultrasound in the measurement of the arterial intima-media thickness. Reumatismo 59:38-49

40. Kobayashi H, Giles JT, Polak JF, Blumenthal RS, Leffell MS, Szklo M, Petri M, Gelber AC, Post W, Bathon JM (2010) Increased prevalence of carotid artery atherosclerosis in rheumatoid arthritis is artery-specific. J Rheumatol 37(4):730-739

41. Schott LL, Kao AH, Cunningham A, Wildman RP, Kuller LH, Sutton-Tyrrell K, Wasko MC (2009) Do carotid artery diameters manifest early evidence of atherosclerosis in women with rheumatoid arthritis? J Womens Health (2002) 18(1):21-29. https:// doi.org/10.1089/jwh.2008.0797

42. Viswanathan V, Jamthikar AD, Gupta D, Puvvula A, Khanna NN, Saba L, Viskovic K, Mavrogeni S, Turk M, Laird JR, Pareek G, Miner M, Ajuluchukwu JNA, Sfikakis PP, Protogerou A, Kitas GD, Nicolaides A, Sharma A, Suri JS (2020) Integration of eGFR biomarker in image-based CV/stroke risk calculator: a south Asian-Indian diabetes cohort with moderate chronic kidney disease. Int Angiol. https://doi.org/10.23736/s0392 $-9590.20 .04338-2$

43. Khanna NN, Jamthikar AD, Gupta D, Araki T, Piga M, Saba L, Carcassi C, Nicolaides A, Laird JR, Suri HS, Gupta A, Mavrogeni S, Protogerou AD, Sfikakis P, Kitas GD, Suri JS (2019) Effect of carotid image-based phenotypes on cardiovascular risk calculator: AECRS1. 0. Med Biol Eng Comput 57(7):1553-1566

44. Khanna NN, Jamthikar AD, Araki T, Gupta D, Piga M, Saba L, Carcassi C, Nicolaides A, Laird JR, Suri HS, Gupta A, Mavrogeni S, Kitas GD, Suri JS (2019) Nonlinear model for the carotid artery disease 10-year risk prediction by fusing conventional cardiovascular factors to carotid ultrasound image phenotypes: a Japanese diabetes cohort study. Echocardiography 36(2):345-361

45. Khanna NN, Jamthikar AD, Gupta D, Nicolaides A, Araki T, Saba L, Cuadrado-Godia E, Sharma A, Omerzu T, Suri HS, Gupta A, Mavrogeni S, Turk M, Laird JR, Protogerou AD, Sfikakis P, Kitas GD, Viswanathan V, Suri JS (2019) Performance evaluation of 10-year ultrasound image-based stroke/cardiovascular $(\mathrm{CV})$ risk calculator by comparing against ten conventional CV risk calculators: a diabetic study. Comput Biol Med 105:125-143

46. Saba L, Biswas M, Kuppili V, Godia EC, Suri HS, Edla DR, Omerzu T, Laird JR, Khanna NN, Mavrogeni S (2019) The present and future of deep learning in radiology. Eur J Radiol 114:10-24

47. Araki T, Jain PK, Suri HS, Londhe ND, Ikeda N, El-Baz A, Shrivastava VK, Saba L, Nicolaides A, Shafique S (2017) Stroke risk stratification and its validation using ultrasonic Echolucent Carotid Wall plaque morphology: a machine learning paradigm. Comput Biol Med 80:77-96

48. Acharya UR, Swapna G, Sree SV, Molinari F, Gupta S, Bardales RH, Witkowska A, Suri JS (2014) A review on ultrasound-based thyroid cancer tissue characterization and automated classification. Technol Cancer Res Treat 13(4):289-301

49. Saba L, Dey N, Ashour AS, Samanta S, Nath SS, Chakraborty S, Sanches J, Kumar D, Marinho R, Suri JS (2016) Automated stratification of liver disease in ultrasound: an online accurate feature classification paradigm. Comput Methods Progr Biomed 130:118-134. https://doi.org/10.1016/j.cmpb.2016.03.016 
50. Tandel G, Biswas M, Kakde OG, Tiwari A, Suri HS, Turk M, Laird JR, Asare CK, Ankrah AA, Khanna NN, Madhusudhan BK, Saba L, Suri JS (2019) A review on a deep learning perspective in brain cancer classification. Cancers 11(1):111. https://doi. org/10.3390/cancers11010111

51. Jamthikar A, Gupta D, Saba L, Khanna NN, Araki T, Viskovic K, Mavrogeni S, Laird JR, Pareek G, Miner M, Sfikakis PP, Protogerou A, Viswanathan V, Sharma A, Nicolaides A, Kitas GD, Suri JS (2020) Cardiovascular/stroke risk predictive calculators: a comparison between statistical and machine learning models. Cardiovasc Diagn Ther 10:921-938

52. Jamthikar A, Gupta D, Cuadrado-Godia E, Puvvula A, Khanna NN, Saba L, Viskovic K, Mavrogeni S, Turk M, Laird JR, Pareek G, Miner M, Sfikakis PP, Protogerou A, Kitas GD, Shankar C, Nicolaides A, Viswanathan V, Sharma A, Suri JS (2020) Ultrasound-based stroke/cardiovascular risk stratification using Framingham Risk Score and ASCVD Risk Score based on "Integrated Vascular Age" instead of "Chronological Age": a multiethnic study of Asian Indian, Caucasian, and Japanese cohorts. Cardiovasc Diagn Ther 10:939-954

53. McClure P, Elnakib A, El-Ghar MA, Khalifa F, Soliman A, ElDiasty T, Suri JS, Elmaghraby A, El-Baz A (2014) In-vitro and in vivo diagnostic techniques for prostate cancer: a review. J Biomed Nanotechnol 10(10):2747-2777

54. Jamthikar A, Gupta D, Khanna NN, Saba L, Araki T, Viskovic K, Suri HS, Gupta A, Mavrogeni S, Turk M, Laird JR, Pareek G, Miner M, Sfikakis PP, Protogerou A, Kitas GD, Viswanathan V, Nicolaides A, Bhatt DL, Suri JS (2019) A low-cost machine learning-based cardiovascular/stroke risk assessment system: integration of conventional factors with image phenotypes. Cardiovasc Diagn Ther 9(5):420-430. https://doi.org/10.21037/ cdt.2019.09.03

55. Kakadiaris IA, Vrigkas M, Yen AA, Kuznetsova T, Budoff M, Naghavi M (2018) Machine learning outperforms ACC/ AHA CVD risk calculator in MESA. J Am Heart Assoc 7(22): 009476

56. Weng SF, Reps J, Kai J, Garibaldi JM, Qureshi N (2017) Can machine-learning improve cardiovascular risk prediction using routine clinical data? PLoS One 12(4):e0174944

57. Zhou S-M, Fernandez-Gutierrez F, Kennedy J, Cooksey R, Atkinson M, Denaxas S, Siebert S, Dixon WG, O'Neill TW, Choy E, Sudlow C, Follow-up UKB, Outcomes G, Brophy S (2016) Defining disease phenotypes in primary care electronic health records by a machine learning approach: a case study in identifying rheumatoid arthritis. PLoS One 11(5):e0154515. https://doi.org/10.1371/journal.pone.0154515

58. Lin C, Karlson EW, Canhao H, Miller TA, Dligach D, Chen PJ, Perez RNG, Shen Y, Weinblatt ME, Shadick NA, Plenge RM, Savova GK (2013) Automatic prediction of rheumatoid arthritis disease activity from the electronic medical records. PLoS One 8(8):e69932. https://doi.org/10.1371/journal.pone.0069932

59. Orange DE, Agius P, DiCarlo EF, Robine N, Geiger H, Szymonifka J, McNamara M, Cummings R, Andersen KM, Mirza S, Figgie M, Ivashkiv LB, Pernis AB, Jiang CS, Frank MO, Darnell RB, Lingampali N, Robinson WH, Gravallese E, Arthritis tAMPiR, Network L, Bykerk VP, Goodman SM, Donlin LT (2018) Identification of three rheumatoid arthritis disease subtypes by machine learning integration of synovial histologic features and RNA sequencing data. Arthritis Rheumatol 70(5):690-701. https ://doi.org/10.1002/art.40428

60. Lezcano-Valverde JM, Salazar F, León L, Toledano E, Jover JA, Fernandez-Gutierrez B, Soudah E, González-Álvaro I, Abasolo L, Rodriguez-Rodriguez L (2017) Development and validation of a multivariate predictive model for rheumatoid arthritis mortality using a machine learning approach. Sci Rep 7(1):10189. https:// doi.org/10.1038/s41598-017-10558-w
61. Gasparyan AY, Ayvazyan L, Blackmore H, Kitas GD (2011) Writing a narrative biomedical review: considerations for authors, peer reviewers, and editors. Rheumatol Int 31(11):1409

62. Sattar N, McCarey DW, Capell H, McInnes IB (2003) Explaining how "high-grade" systemic inflammation accelerates vascular risk in rheumatoid arthritis. Circulation 108(24):2957-2963

63. Munzel T, Heitzer T, Harrison DG (1997) The physiology and pathophysiology of the nitric oxide/superoxide system. Herz 22(3): 158-172

64. Safar ME, Asmar R, Benetos A, Blacher J, Boutouyrie P, Lacolley P, Laurent S, London G, Pannier B, Protogerou A (2018) Interaction between hypertension and arterial stiffness: an expert reappraisal. Hypertension 72(4):796-805

65. Yuri Gasparyan A, Ayvazyan L, Cocco G, Kitas DG (2012) Adverse cardiovascular effects of antirheumatic drugs: implications for clinical practice and research. Curr Pharm Des 18(11):1543-1555

66. Panoulas VF, Metsios GS, Pace A, John H, Treharne G, Banks M, Kitas GD (2008) Hypertension in rheumatoid arthritis. Rheumatology 47(9):1286-1298

67. Van Halm V, Nielen M, Nurmohamed M, Van Schaardenburg D, Reesink H, Voskuyl A, Twisk J, Van de Stadt R, De Koning M, Habibuw M (2007) Lipids and inflammation: serial measurements of the lipid profile of blood donors who later developed rheumatoid arthritis. Ann Rheum Dis 66(2):184-188

68. Toms ET, Symmons PD, Kitas DG (2010) Dyslipidaemia in rheumatoid arthritis: the role of inflammation, drugs, lifestyle and genetic factors. Curr Vasc Pharmacol 8(3):301-326

69. Toms TE, Panoulas VF, Douglas KM, Nightingale P, Smith JP, Griffiths H, Sattar N, Symmons DP, Kitas GD (2011) Are lipid ratios less susceptible to change with systemic inflammation than individual lipid components in patients with rheumatoid arthritis? Angiology 62(2):167-175. https://doi.org/10.1177/00033 19710373749

70. Summers GD, Metsios GS, Stavropoulos-Kalinoglou A, Kitas GD (2010) Rheumatoid cachexia and cardiovascular disease. Nat Rev Rheumatol 6(8):445

71. Rall L, Roubenoff R (2004) Rheumatoid cachexia: metabolic abnormalities, mechanisms and interventions. Rheumatology 43(10):1219-1223

72. Guttridge DC, Mayo MW, Madrid LV, Wang C-Y, Baldwin AS Jr (2000) NF- $\kappa$ B-induced loss of MyoD messenger RNA: possible role in muscle decay and cachexia. Science 289(5488):2363-2366

73. Lemmey AB (2015) Rheumatoid cachexia: the undiagnosed, untreated key to restoring physical function in rheumatoid arthritis patients? Rheumatology 55(7):1149-1150. https://doi. org/10.1093/rheumatology/kev412

74. Elkan A-C, Engvall I-L, Cederholm T, Hafström I (2009) Rheumatoid cachexia, central obesity and malnutrition in patients with low-active rheumatoid arthritis: feasibility of anthropometry, Mini Nutritional Assessment and body composition techniques. Eur J Nutr 48(5):315-322

75. Stavropoulos-Kalinoglou A, Metsios GS, Panoulas VF, Nevill AM, Jamurtas AZ, Koutedakis Y, Kitas GD (2009) Underweight and obese states both associate with worse disease activity and physical function in patients with established rheumatoid arthritis. Clin Rheumatol 28(4):439-444

76. Da Cunha V, Brenol C, Brenol J, Fuchs S, Arlindo E, Melo I, Machado C, de Castro Chaves H Jr, Xavier R (2012) Metabolic syndrome prevalence is increased in rheumatoid arthritis patients and is associated with disease activity. Scand J Rheumatol 41(3):186-191

77. Shahin D, Eltoraby E, Mesbah A, Houssen M (2010) Insulin resistance in early untreated rheumatoid arthritis patients. Clin Biochem 43(7-8):661-665 
78. Natali $\mathrm{A}$, Toschi E, Baldeweg $\mathrm{S}$, Ciociaro $\mathrm{D}$, Favilla $\mathrm{S}$, Saccà L, Ferrannini E (2006) Clustering of insulin resistance with vascular dysfunction and low-grade inflammation in type 2 diabetes. Diabetes 55(4):1133-1140. https://doi.org/10.2337/diabe tes.55.04.06.db05-1076

79. Pamuk ON, Unlü E, Cakir N (2006) Role of insulin resistance in increased frequency of atherosclerosis detected by carotid ultrasonography in rheumatoid arthritis. J Rheumatol 33(12):2447-2452

80. Libby P (2006) Inflammation and cardiovascular disease mechanisms. Am J Clin Nutr 83(2):456S-460S

81. Duerden M, O'Flynn N Qureshi N (2015) Cardiovascular risk assessment and lipid modification: NICE guideline. British J GenPract 65(636):378-380

82. Anderson TJ, Grégoire J, Pearson GJ, Barry AR, Couture P, Dawes M, Francis GA, Genest J, Grover S, Gupta M, Hegele RA, Lau DC, Leiter LA, Lonn E, Mancini GBJ, McPherson R, Ngui D, Poirier P, Sievenpiper JL, Stone JA, Thanassoulis G, Ward R (2016) 2016 Canadian Cardiovascular Society Guidelines for the management of dyslipidemia for the prevention of cardiovascular disease in the adult. Can J Cardiol 32(11):1263-1282. https://doi. org/10.1016/j.cjca.2016.07.510

83. Mendis S, Lindholm LH, Mancia G, Whitworth J, Alderman M, Lim S, Heagerty T (2007) World Health Organization (WHO) and International Society of Hypertension (ISH) risk prediction charts: assessment of cardiovascular risk for prevention and control of cardiovascular disease in low and middle-income countries. J Hypertens 25(8):1578-1582

84. Lagrand WK, Visser CA, Hermens WT, Niessen HWM, Verheugt FWA, Wolbink G-J, Hack CE (1999) C-reactive protein as a cardiovascular risk factor. Circulation 100(1):96-102. https ://doi.org/10.1161/01.CIR.100.1.96

85. Rajagopalan V, Alemao E, Kawabata H, Solomon D (2014) SAT0069 performance of the Framingham Cardiovascular risk prediction model with and without $\mathrm{C}$-reactive protein or erythrocyte sedimentation rate in RA: analysis of US electronic medical records database. Ann Rheum Dis 73(Suppl 2):615

86. van der Heijde D, Ramiro S, Landewé R, Baraliakos X, Van den Bosch F, Sepriano A, Regel A, Ciurea A, Dagfinrud H, Dougados M (2017) 2016 update of the ASAS-EULAR management recommendations for axial spondyloarthritis. Ann Rheum Dis 76(6):978-991

87. Curtis J, Xie F, Crowson C, Mabey B, Flake D, Bamford R, Chin C, Sasso E, Hitraya E, Ben-Shachar R (2020) FRI0553 Development and validation of a biomarker-based cardiovascular risk prediction score in rheumatoid arthritis. BMJ 71:2350

88. Wahlin B, Innala L, Magnusson S, Möller B, Smedby T, Rantapää-Dahlqvist S, Wållberg-Jonsson S (2019) Performance of the expanded cardiovascular risk prediction score for rheumatoid arthritis is not superior to the ACC/AHA Risk calculator. J Rheumatol 46(2):130-137

89. Corrales A, Dessein PH, Tsang L, Pina T, Blanco R, GonzalezJuanatey C, Llorca J, Gonzalez-Gay MA (2015) Carotid artery plaque in women with rheumatoid arthritis and low estimated cardiovascular disease risk: a cross-sectional study. Arthritis Res Ther 17(1):55

90. Fent GJ, Greenwood JP, Plein S, Buch MH (2017) The role of non-invasive cardiovascular imaging in the assessment of cardiovascular risk in rheumatoid arthritis: where we are and where we need to be. Ann Rheum Dis 76(7):1169

91. Yoon HE, Kim Y, Kim SD, Oh JK, Chung Y-A, Shin SJ, Yang CW, Seo SM (2018) A pilot trial to examine the changes in carotid arterial inflammation in renal transplant recipients as assessed by $18 \mathrm{~F}$-fluorodeoxyglucose (18F-FDG) positron emission tomography computed tomography (PET/CT). Ann
Transplant 23:412-421. https://doi.org/10.12659/AOT.90921 2

92. Viswanathan V, Jamthikar AD, Gupta D, Shanu N, Puvvula A, Khanna NN, Saba L, Omerzum T, Viskovic K, Mavrogeni S, Turk M, Laird JR, Pareek G, Miner M, Sfikakis PP, Protogerou A, Kitas GD, Joshi SCS, Fiscian H, Folson AA, Wu DH, Ruzsa Z, Nicolaides A, Sharma A, Bhatt DL, Suri JS (2020) Low-cost preventive screening using carotid ultrasound in patients with diabetes. Front Biosci (Landmark Ed) 25:1132-1171

93. Ristić GG, Lepić T, Glišić B, Stanisavljević D, Vojvodić D, Petronijević M, Stefanović D (2010) Rheumatoid arthritis is an independent risk factor for increased carotid intima-media thickness: impact of anti-inflammatory treatment. Rheumatology 49(6):1076-1081

94. Viswanathan V, Jamthikar AD, Gupta D, Puvvula A, Khanna NN, Saba L, Viskovic K, Mavrogeni S, Laird JR, Pareek G, Miner M, Sfikakis PP, Protogerou A, Kitas GD, Nicolaides A, Sharma A, Suri JS (2020) Does the carotid bulb offer a better 10-year CVD/stroke risk assessment compared with the common carotid artery?: a 1516 ultrasound scan study. Angiology. https:// doi.org/10.1177/0003319720941730

95. Lind L, Gigante B, Borne Y, Mälarstig A, Sundström J, Ärnlöv J, Ingelsson E, Baldassarre D, Tremoli E, Veglia F (2020) The plasma protein profile and cardiovascular risk differ between intima-media thickness of the common carotid artery and the bulb: a meta-analysis and a longitudinal evaluation. Atherosclerosis 295:25-30

96. Gregg S, Li TY, Hétu M-F, Pang SC, Ewart P, Johri AM (2018) Relationship between carotid artery atherosclerosis and bulb geometry. Int J Cardiovasc Imaging 34(7):1081-1090

97. Okazaki S, Sakaguchi M, Miwa K, Furukado S, Yamagami H, Yagita Y, Mochizuki H, Kitagawa K (2014) Association of interleukin- 6 with the progression of carotid atherosclerosis: a 9-year follow-up study. Stroke 45(10):2924-2929. https://doi. org/10.1161/strokeaha.114.005991

98. Yayan J (2012) Erythrocyte sedimentation rate as a marker for coronary heart disease. Vasc Health Risk Manag 8:219

99. Andresdottir MB, Sigfusson N, Sigvaldason H, Gudnason V (2003) Erythrocyte sedimentation rate, an independent predictor of coronary heart disease in men and women: the Reykjavik Study. Am J Epidemiol 158(9):844-851. https://doi.org/10.1093/ aje/kwg222

100. Natali A, L'Abbate A, Ferrannini E (2003) Erythrocyte sedimentation rate, coronary atherosclerosis, and cardiac mortality. Eur Heart J 24(7):639-648

101. Xie D, Hu D, Zhang Q, Sun Y, Li J, Zhang Y (2016) Increased high-sensitivity C-reactive protein, erythrocyte sedimentation rate and lactic acid in stroke patients with internal carotid artery occlusion. Arch Med Sci 12(3):546-551. https://doi.org/10.5114/ aoms.2014.47879

102. Eftekhaari TE (2012) ESR rate can be a marker for coronary artery disease. Vasc Health Risk Manag 8:669-670. https://doi. org/10.2147/VHRM.S39006

103. Sander D, Schulze-Horn C, Bickel H, Gnahn H, Bartels E, Con$\operatorname{rad} \mathrm{B}$ (2006) Combined effects of hemoglobin A1c and C-reactive protein on the progression of subclinical carotid atherosclerosis: the INVADE study. Stroke 37(2):351-357

104. van der Meer IM, de Maat MP, Hak AE, Kiliaan AJ, Del Sol AI, van der Kuip DA, Nijhuis RL, Hofman A, Witteman JC (2002) $\mathrm{C}$-reactive protein predicts progression of atherosclerosis measured at various sites in the arterial tree: the Rotterdam Study. Stroke 33(12):2750-2755

105. Toprak A, Kandavar R, Toprak D, Chen W, Srinivasan S, Xu $\mathrm{JH}$, Anwar A, Berenson GS (2011) C-reactive protein is an independent predictor for carotid artery intima-media thickness 
progression in asymptomatic younger adults (from the Bogalusa Heart Study). BMC Cardiovasc Disord 11(1):78

106. Nambi V, Chambless L, Folsom AR, He M, Hu Y, Mosley T, Volcik K, Boerwinkle E, Ballantyne CM (2010) Carotid intimamedia thickness and presence or absence of plaque improves prediction of coronary heart disease risk: the ARIC (Atherosclerosis Risk In Communities) study. J Am Coll Cardiol 55(15):1600-1607

107. Biswas M, Kuppili V, Saba L, Edla DR, Suri HS, CuadradoGodia E, Laird JR, Marinhoe RT, Sanches JM, Nicolaides A (2019) State-of-the-art review on deep learning in medical imaging. Front Biosci (Landmark edition) 24:392-426

108. El-Baz A, Suri JS (2011) Lung imaging and computer aided diagnosis. CRC Press, Boca Raton

109. Li L, Qin L, Xu Z, Yin Y, Wang X, Kong B, Bai J, Lu Y, Fang Z, Song Q (2020) Artificial intelligence distinguishes COVID-19 from community acquired pneumonia on chest CT. Radiology 296:65-72

110. Ilyas M, Rehman H, Naït-Ali A (2020) Detection of Covid-19 from chest X-ray images using artificial intelligence: an early review. arXiv preprint arXiv:200405436

111. Biswas M, Kuppili V, Saba L, Edla DR, Suri HS, Sharma A, Cuadrado-Godia E, Laird JR, Nicolaides A, Suri JS (2019) Deep learning fully convolution network for lumen characterization in diabetic patients using carotid ultrasound: a tool for stroke risk. Med Biol Eng Comput 57(2):543-564

112. Skandha S, Gupta S, Saba L, Koppula V, Suri JS (2020) Ultrasound-based carotid plaque tissue risk stratification using 3-D optimized artificial intelligence paradigm: a cardiovascular/ stroke application: atheromatic 2.0. Comput Biol Med. https:// doi.org/10.1016/j.compbiomed.2020.103958

113. Svanteson M, Rollefstad S, Kløw NE, Hisdal J, Ikdahl E, Semb AG, Haig Y (2017) Associations between coronary and carotid artery atherosclerosis in patients with inflammatory joint diseases. RMD Open 3(2):e000544. https://doi.org/10.1136/rmdop en-2017-000544

114. Danesh J, Wheeler JG, Hirschfield GM, Eda S, Eiriksdottir G, Rumley A, Lowe GD, Pepys MB, Gudnason V (2004) C-reactive protein and other circulating markers of inflammation in the prediction of coronary heart disease. N Engl J Med 350(14):13871397. https://doi.org/10.1056/NEJMoa032804

115. Timmer JR, Ottervanger JP, Hoorntje JC, DeBoer MJ, Suryapranata H, Van't Hof AW, Zijlstra F, Group TZMIS (2005) Prognostic value of erythrocyte sedimentation rate in ST segment elevation myocardial infarction: interaction with hyperglycaemia. J Intern Med 257(5):423-429. https://doi.org/10.111 $1 / j .1365-2796.2005 .01478 . x$

116. Gastounioti A, Makrodimitris S, Golemati S, Kadoglou NP, Liapis CD, Nikita KS (2015) A novel computerized tool to stratify risk in carotid atherosclerosis using kinematic features of the arterial wall. IEEE J Biomed Health Inform 19(3):1137-1145

117. Unnikrishnan P, Kumar DK, Poosapadi Arjunan S, Kumar H, Mitchell P, Kawasaki R (2016) Development of health parameter model for risk prediction of CVD using SVM. Comput Math Methods Med 2016:1-7

118. Ambale-Venkatesh B, Wu CO, Liu K, Hundley W, McClelland RL, Gomes AS, Folsom AR, Shea S, Guallar E, Bluemke DA (2017) Cardiovascular event prediction by machine learning: the Multi-Ethnic Study of Atherosclerosis. Cir Res CIRCRESAHA 121:1092-1101

119. Banchhor SK, Londhe ND, Araki T, Saba L, Radeva P, Laird JR, Suri JS (2017) Wall-based measurement features provides an improved IVUS coronary artery risk assessment when fused with plaque texture-based features during machine learning paradigm. Comput Biol Med 91:198-212

120. Jamthikar A, Gupta D, Khanna NN, Saba L, Laird JR, Suri JS (2020) Cardiovascular/stroke risk prevention: a new machine learning framework integrating carotid ultrasound image-based phenotypes and its harmonics with conventional risk factors. Indian Heart J. https://doi.org/10.1016/j.ihj.2020.06.004

Publisher's Note Springer Nature remains neutral with regard to jurisdictional claims in published maps and institutional affiliations.

\section{Affiliations}

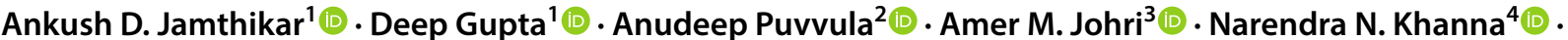

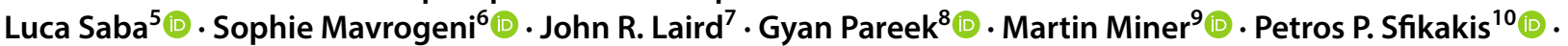

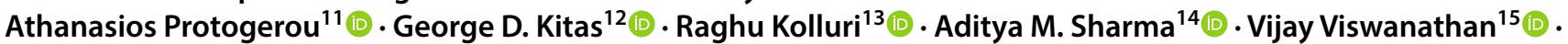 Vijay S. Rathore ${ }^{16}$ (D) Jasjit S. Suri ${ }^{17}$}

\author{
Ankush D. Jamthikar \\ ankush.jamthikar1992@gmail.com \\ Deep Gupta \\ er.deepgupta@gmail.com \\ Anudeep Puvvula \\ dr.anudeeppuvvula@gmail.com \\ Amer M. Johri \\ johria@queensu.ca \\ Narendra N. Khanna \\ drnnkhanna@gmail.com \\ Luca Saba \\ lucasabamd@gmail.com \\ Sophie Mavrogeni \\ soma13@otenet.gr
}

John R. Laird

lairdjr@ah.org

Gyan Pareek

gyan_pareek@brown.edu

Martin Miner

martin_miner@brown.edu

Petros P. Sfikakis

psfikakis@med.uoa.gr

Athanasios Protogerou

aprotog@med.uoa.gr

George D. Kitas

kitas@dgh.nhs.uk

Raghu Kolluri

kolluri.raghu@gmail.com 
Aditya M. Sharma

AS8AH@hscmail.mcc.virginia.edu

Vijay Viswanathan

drvijay@mvdiabetes.com

Vijay S. Rathore

Vijay.s.rathore@kp.org

1 Department of Electronics and Communications Engineering, Visvesvaraya National Institute of Technology, Nagpur, MH, India

2 Annu's Hospitals for Skin and Diabetes, Nellore, AP, India

3 Department of Medicine, Division of Cardiology, Queen's University, Kingston, ON, Canada

4 Department of Cardiology, Indraprastha APOLLO Hospitals, New Delhi, India

5 Department of Radiology, Azienda Ospedaliero Universitaria (A.O.U.), Cagliari, Italy

6 Cardiology Clinic, Onassis Cardiac Surgery Center, Athens, Greece

7 Heart and Vascular Institute, Adventist Health St. Helena, St Helena, CA, USA
8 Minimally Invasive Urology Institute, Brown University, Providence, RI, USA

9 Men's Health Center, Miriam Hospital, Providence, RI, USA

10 Rheumatology Unit, National Kapodistrian University of Athens, Athens, Greece

11 Department of Cardiovascular Prevention, National and Kapodistrian University of Athens, Athens, Greece

12 Department of Rheumatology, Dudley Group NHS Foundation Trust, Dudley, UK

13 OhioHealth Heart and Vascular, Columbus, OH, USA

14 Division of Cardiovascular Medicine, University of Virginia, Charlottesville, VA, USA

15 MV Hospital for Diabetes and Professor M Viswanathan Diabetes Research Centre, Chennai, India

16 Nephrology Department, Kaiser Permanente, Sacramento, CA, USA

17 Stroke Monitoring and Diagnostic Division, AtheroPoint ${ }^{\mathrm{TM}}$, Roseville, CA 95661, USA 